\title{
NOTAS SOBRE O FENOMENOLÓGICO EM MUNDO E HISTORICIDADE - VOL.1
}

\author{
Paulo Taddei *
}

CASANOVA, Marco Antonio. Mundo e Historicidade: leituras fenomenológicas de Ser e tempo. Volume 1 - Existência e Mundaneidade. 1ํㅡㄹ Edição. Rio de Janeiro: Via Vérita, 2017. ISBN: 978-856456565-4.

Mundo e Historicidade: leituras fenomenológicas de Ser e tempo. Volume 1 Existência e Mundaneidade, obra do professor Marco Antonio Casanova, pesquisador consolidado em Filosofia no Brasil e no mundo e, dentre outras coisas, especialista inconteste na obra de Heidegger, representa uma inestimável contribuição acadêmica para o público brasileiro, vindo, com efeito, a preencher uma significativa lacuna bibliográfica nas introduções a Ser e Tempo no Brasil. Antes, um iniciante em Heidegger podia contar tanto com a introdução de Nunes, ${ }^{1}$ que, embora peque pela brevidade, certamente cumpre com excelência os requisitos de uma apresentação inicial de Ser e Tempo, quanto com os textos mais antigos de Stein, ${ }^{2}$ que, embora mais exigentes, são também menos sistemáticos no acompanhamento da obra. Se quisesse avançar no estudo da literatura secundária, nosso hipotético iniciante deveria saltar para obras como o desafiador ensaio de Reis, ${ }^{3}$ que

\footnotetext{
* Doutor em Filosofia pela UFRJ com estadia sanduíche na Philipps Universität Marburg. Professor de Filosofia do Departamento de Psicologia Geral e Experimental da UFRJ e professor permanente do Programa de Pós-Graduação em Filosofia da mesma Universidade. ${ }^{1}$ NUNES, Benedito. (2002). Heidegger \& Ser e Tempo. Coleção Filosofia Passo-a-passo 6. $3^{\text {a }}$ ed. Rio de Janeiro: Zahar, 2010.

2 STEIN, Ernildo. (1988). Seis Estudos sobre "Ser e Tempo". Petrópolis: Vozes, 1990.

${ }^{3}$ REIS, Robson R. Aspectos da modalidade: a noção de possibilidade na fenomenologia hermenêutica. 1ํㅡㄹ. Rio de Janeiro: Via Vérita, 2014.
} 
perpassa diversos volumes da Gesamtausgabe em busca da clarificação da noção de possibilidade existencial. Com a publicação do primeiro volume de Mundo e Historicidade, temos disponível um comentário que se insere em um importante nível intermediário: uma introdução minuciosa da primeira seção de Ser e Tempo, que, ao mesmo tempo que é acessível ao iniciante, faculta-lhe o caminho para pesquisas futuras sobre e em torno de Heidegger. Trata-se indubitavelmente de leitura obrigatória tanto para estudantes de graduação em Filosofia e em áreas afins - especialmente em Psicologia -, como para estudantes de pós-graduação dessas áreas que estejam se iniciando em Heidegger, como ainda para pesquisadores em geral cujos interesses de pesquisa se voltem para a tradição da fenomenologia. Pelo seu escopo, Mundo e Historicidade se deixa comparar com importantes comentários disponíveis no estrangeiro, como Being-in-the-world, de Dreyfus, ${ }^{4}$ e Verstehen und Auslegung, de Gethmann, ${ }^{5}$ obras que, em seus respectivos países, abriram caminho para novas interpretações de Ser e Tempo ao tornar o texto de Heidegger acessível a um público mais amplo: Dreyfus aproximou Heidegger da ciência cognitiva, e Gethmann aproximou o autor alemão da epistemologia construtivista da Escola de Erlangen.

Diferentemente dessas introduções, contudo, Mundo e Historicidade opta, de início, por uma reconstrução hermenêutica em lugar de uma reconstrução meramente analítica. A oposição entre hermenêutico e meramente analítico oferece-nos o próprio Casanova. ${ }^{6}$ Dado o caráter declaradamente hermenêutico de Ser e Tempo, é inegável a adequação desse ponto de partida e se Von Hermann não houvesse intitulado sua obra a autointerpretação de Heidegger, certamente Casanova teria aqui o direito de fazê-lo. Vale, de início, examinar mais detidamente essa oposição que norteia o trabalho.

Uma atitude analítica diante de uma obra seria responsável por engendrar análises conceituais e reconstruções argumentativas, de modo a lançar luz sobre cada uma de suas partes constituintes; embora indispensável em qualquer interpretação, ela precisaria, segundo Casanova, necessariamente "ser transcendida". Essa insuficiência do trabalho meramente analítico se ligaria a certo caráter paradoxal de toda interpretação de uma obra - de um lado, o todo da obra só pode ser reconstruído por suas partes; por outro, cada parte só pode aparecer como parte à luz de um todo. Não é outra a formulação de Figal do círculo hermenêutico:

Em termos gerais o que se tem em vista com tal círculo é o estado de coisas, segundo o qual o particular sempre precisa ser interpretado a partir do

\footnotetext{
${ }^{4}$ DREYFUS, Hubert. Being-in-the-world - Commentary on Being and Time Division 1. MIT Press, 1991.

${ }^{5}$ GETHMANN, C. F. Verstehen und Auslegung: das Methodenproblem in Martin Heideggers Philosophie. Bouvier Verlag: 1974.

${ }^{6}$ CASANOVA, Marco Antonio. Mundo e historicidade: leituras fenomenológicas de Ser e Tempo - vol. 1: existência e mundaneidade. Rio de Janeiro: Via Verita, 2017, p. 7-8.
} 
todo ao qual pertence, e segundo o qual o todo não pode ser descerrado senão por meio de uma compreensão das particularidades. ${ }^{7}$

Por óbvio, o trabalho meramente analítico pode ser útil no que se refere à determinação de partes, mas permanece insensível com relação à iluminação que uma compreensão prévia do todo já sempre efetivou para que algo como uma parte possa aparecer como tal. Desse modo, é necessária uma abordagem hermenêutica, o que aqui significa: uma abordagem que esteja atenta ao "todo da obra, que ressoa em cada uma de suas notas singulares" ${ }^{8}$ Alhures, ${ }^{9}$ caracterizei, tomando de empréstimo expressão cara à tradição da pragmática, tal atitude de sensibilidade hermenêutica: é preciso disciplinar o afã de decomposição da obra com o auxílio de um senso de qual compreensão do todo já está previamente nos guiando. Enquanto atenção e cuidado respectivamente à totalidade da obra, a sensibilidade hermenêutica seria, assim, insubstituível.

É inegável que o comentário de Casanova atinge plenamente seu objetivo: afina-se com o todo dessa obra e faz, indubitavelmente, ressoar as partes que a compõem. Não se pode deixar de considerar, todavia, que a decisão de guiar-se pelo todo pode significar o sacrifício de certos detalhes. $\mathrm{O}$ objetivo dessa nota bibliográfica não é o de sumarizar esse comentário integralmente - o que já foi feito a contento alhures. ${ }^{10}$ Trago, antes, ponderações que, conquanto pontuais, indicam certas pendências ou lacunas em um comentário voltado, sobretudo, para o leitor interessado em prosseguir em pesquisas sobre ou em torno de Heidegger. Num primeiro momento, abordarei questões de ordem formal para, num segundo momento, tratar de questões de natureza conteudística.

De início, vale destacar que a falta mais flagrante no primeiro volume de Mundo e Historicidade é a de um glossário de tradução dos principais termos de Ser e Tempo acompanhado das devidas elucidações do tradutor. Notam-se no comentário - e a bem dizer ao longo da extensa obra do professor Casanova - opções específicas para a tradução de termos centrais de Ser e Tempo, como, para citar apenas dois exemplos, Dasein e Vorhandenheit. Como é sabido, já há disponível no português brasileiro duas traduções diferentes de Ser e Tempo, uma, da professora Márcia de Sá Cavalcante Schuback, com numerosas edições e revisões, e outra, do professor Fausto Castilho, um cenário que torna a publicação de uma terceira tradução um empreendimento algo ocioso. Não obstante, em se tratando de um espe-

\footnotetext{
${ }^{7}$ FIGAL, Günter. Oposicionalidade: o elemento hermenêutico e a filosofia. Trad. Marco Antonio Casanova. Petrópolis: Vozes, 2007, p. 110-111.

${ }^{8}$ CASANOVA, Marco Antonio. Op.Cit., p. 8.

${ }^{9}$ Obra de AUTOR.

${ }^{10}$ CASSIANO, R. R. "Resenha crítica de 'Mundo e historicidade: leituras fenomenológicas de Ser e Tempo - vol. 1: existência e mundaneidade', de Marco Antonio Casanova". In: Ek-stasis - revista de hermenêutica e fenomenologia. Vol. 6, ํㅡ. 2, 2017, p. 7-18.
} 
cialista em Heidegger e de um tradutor consolidado, há razões de sobra para o público estar interessado nas elucidações de Casanova a respeito de suas alternativas de tradução e o cenário acima mencionado torna Mundo e Historicidade, bem como sua continuação com o comentário da segunda seção de Ser e Tempo, o lugar ideal para tal glossário de tradução com as elucidações apropriadas. ${ }^{11}$

Uma segunda ausência significativa é a de uma bibliografia comentada sobre e em torno de Ser e Tempo, que auxilie o interessado em pesquisas mais avançadas a se orientar em meio à diversidade de itens bibliográficos relacionados à obra. É certo que Ser e Tempo ocupa um lugar único na história da filosofia e do pensamento contemporâneos: sua influência se deixa sentir em múltiplas correntes dos séculos XX e XXI e sua literatura secundária reflete esse interesse variegado na obra. Assim, uma bibliografia comentada poderia incluir: (i) as outras obras e escritos de Heidegger mais diretamente relacionados a Ser e Tempo; (ii) as obras de literatura secundária das mais diversas correntes, i.e., existencialista, pós-moderna, analítica, pragmatista, hermenêutica, dentre outras, sobretudo as que surgiram voltadas para os volumes da Gesamtausgabe que antecederam Ser e Tempo; (iii) obras da complexa história dos efeitos de Ser e Tempo, seja de filosofia contemporânea que se deixaram influenciar por Heidegger desde as pós-estruturalistas às da corrente de ciência cognitiva $4 \mathrm{E}$ - seja as de disciplinas afins como da psicologia clínica.

Em terceiro lugar, índice de temas mencionados e índice de autores citados ao longo da obra (os quais em edições alemães aparecem respectivamente como Sach- e Personenregister) fazem igualmente falta num comentário dessa envergadura. Bastante úteis no trabalho acadêmico e presentes necessariamente em publicações acadêmicas internacionais, tais recursos se fazem necessários em um trabalho que certamente será norteador para gerações futuras. Por fim, não se pode deixar de mencionar a necessidade de revisões editoriais mais cuidadosas para as próximas edições.

Passando a considerações de natureza conteudística, algumas questões relativas a pontos específicos do comentário merecem ser levantadas. Eu as apresento aqui sob quatro rubricas: 1) a reconstrução da relação entre os modelos de fenomenologia de Husserl e de Heidegger; 2) a fenomenologia

\footnotetext{
${ }^{11}$ Nesse sentido, o autor protesta em uma breve nota contra a tradução de Zeug por "instrumento", opção feita pelas duas edições brasileiras da obra; antes prefere o autor o termo "utensílio". A razão dessa preferência estaria na inserção ineliminável de todo Zeug em um mundo circundante - a palavra "instrumento" conotaria justamente esse isolamento da coisa relativamente ao seu campo de funcionamento. Resta, contudo, pouco claro, nas comprimidas linhas da nota do autor, por que "utensílio" não sofre do mesmo problema e por que, se é o caso de fazer jus ao caráter contextual do Zeug, não se poderia usar o termo "equipamento". Ver CASANOVA, Marco Antonio. Mundo e historicidade: leituras fenomenológicas de Ser e Tempo - vol. 1: existência e mundaneidade. Rio de Janeiro: Via Verita, 2017, p. 64, n. 36.
} 
do ente à mão e as apropriações de Ser e Tempo por parte da ciência cognitiva contemporânea; 3) o estatuto do ser-com e da alteridade; 4) o sentido originário de verdade e o sentido da suposta retratação posterior em Zur Sache des Denkens. Dados os limites de uma Nota Bibliográfica, não pretendo aqui defender um ponto central através da articulação das diversas questões; posso dizer, ainda assim, que as questões trazidas orbitam em torno do que é - e do que tem nos últimos tempos se tornado - fazer fenomenologia.

No que se refere à relação entre os modelos de fenomenologia de Husserl e Heidegger, não se pode deixar de celebrar Mundo e Historicidade pela justiça que busca fazer à fenomenologia husserliana. Com efeito, comentários clássicos de Ser e Tempo das mais variadas confissões frequentemente viram entre a fenomenologia de Husserl e a de Heidegger apenas uma distância intransponível ou uma ruptura radical, supondo aí que a fenomenologia de Husserl se reduziria a um desdobramento, talvez sofisticado, do pensamento cartesiano. ${ }^{12}$ Evitando uma leitura que aproxima excessivamente Husserl e Heidegger (v. n. 12), Casanova chama atenção para diversas linhas de continuidade entre os autores: o fato de sermos "única e exclusivamente intencionalidade", ${ }^{13}$ o fato de Heidegger não suspender o princípio de todos os princípios, mas "reformulá-lo em seu conteúdo significativo próprio", ${ }^{14}$ o fato de já Husserl criticar o modelo de subjetividade moderna, ${ }^{15} \mathrm{o}$ fato de Heidegger ter pensado seu projeto como concretização da ideia de filosofia como ciência rigorosa. ${ }^{16}$ É certo que essas passagens estão circundadas no texto de Casanova por reconstruções da ruptura de Heidegger respectivamente a Husserl; esse fato, todavia, não retira o mérito que há em localizar essas rupturas mesmas no âmbito de linhas de continuidade subjacentes e amiúde negligenciadas. Enfocarei aqui três pontos relativos às linhas de continuidade entre Heidegger e Husserl:

\footnotetext{
${ }^{12}$ Encontramos tal linha exegética em comentários tão diversos como o analítico/pragmatista de Dreyfus (1991), o hermenêutico/desconstrucionista de Van Buren (1994) e o analítico/ hermenêutico de Carman (2003). Para Van Buren, por exemplo, o elemento fenomenológico é meramente superficial em Heidegger. Cf. Dreyfus, Hubert. Being-in-the-world - Commentary on Being and Time Division 1. MIT Press, 1991; VAN BUREN, John. The Young Heidegger. Rumor of the Hidden King. Indiana University Press, 1994; CARMAN, Taylor. Heidegger's Analytic: Interpretation, Discourse and Authenticity in Being and Time. Cambridge University Press, 2003. Em contraste com esse modo de ler Heidegger, alguns comentadores privilegiaram a continuidade entre Husserl e Heidegger, especialmente Crowell e Overgaard, um modo de leitura que tem suas raízes no comentário clássico de Tugendhat. Cf. CROWELL, Steven G. Husserl, Heidegger and the Space of Meaning: Paths Toward a Transcendental Philosophy. Evanston, IL: Northwestern University Press, 2001; CROWELL, Steven G. Normativity and Phenomenology in Husserl and Heidegger. Cambridge University Press, 2013; OVERGAARD, Søren. Husserl and Heidegger on Being in the World. Kluwer Academic Publishers, 2004; TUGENDHAT, Ernst. Der Wahrheitsbegriff bei Husserl und Heidegger. Walter de Gruyter, 1970.

${ }^{13}$ CASANOVA, Marco Antonio. Mundo e historicidade: leituras fenomenológicas de Ser e Tempo

- vol. 1: existência e mundaneidade. Rio de Janeiro: Via Verita, 2017, p. 31.

${ }^{14}$ Ibidem, p. 56.

${ }^{15}$ Ibidem, p. 192.

${ }^{16}$ Ibidem, p. 192.
} 
1.1 a discussão da noção de intencionalidade; 1.2 o estatuto do princípio de todos os princípios; 1.3 a ingenuidade pré-hermenêutica husserliana.

No espírito da continuidade entre Husserl e Heidegger, Casanova nos chama atenção, de início, para o fato de que a tese de Heidegger de um movimento ekstático do homem é a radicalização da própria noção husserliana de intencionalidade. Se Husserl, por seu turno, não logrou levar essa noção à sua "máxima radicalidade", ${ }^{17}$ Heidegger o pôde fazer, pois, diferentemente de Husserl, deixou de lado qualquer referência a consciência, a sínteses de vivências, a campos de realização de atos, etc. Desse modo, a consideração heideggeriana de que somos, enquanto entes dotados de caráter de Dasein, fundamentalmente atravessados por um movimento de exposição é, enfim, a radicalização da noção de que o homem é não tanto consciência intencional, mas sim única e exclusivamente intencional. ${ }^{18}$ É a própria noção de intencionalidade enquanto tal que encaminha a posição heideggeriana de superação da metafísica da consciência.

Não há o que se objetar a esse modo de reconstruir a relação: ele ecoa passagens célebres de volumes da Gesamtausgabe em que Heidegger trata do tema da transcendência, distinguindo transcendência ôntica de transcendência ontológica. ${ }^{19}$ A questão que vejo diz respeito à escala da reviravolta que essa mudança operada por Heidegger realiza na economia conceitual da fenomenologia husserliana: parte do desafio de qualquer leitura que queira fazer jus à continuidade entre Husserl e Heidegger, que passagens como a citada sugerem, é reconhecer a magnitude dessa reviravolta sem recair no expediente fácil de considerar Husserl um autor meramente cartesiano. Consideremos a passagem abaixo, extraída do fim da subseção em questão:

Portanto, ao reduzir a consciência intencional husserliana à pura e simples ekstase, o que Heidegger faz é literalmente afirmar que o homem é constituído originariamente por um movimento de ser para fora. Contra o pressuposto moderno mais evidente, contra a posição, por exemplo, fichteana de que toda consciência é necessária e originariamente consciência de si, Heidegger suprime toda e qualquer possibilidade de se falar de uma interioridade inicial que condicionaria em seguida a experiência da exterioridade. Nós nunca estamos primeiro dentro, para posteriormente experimentarmos o fora, mas ao contrário nós já estamos sempre fora, jogados em um campo para o qual toda interioridade não apenas é inacessível, mas também inútil..20

Embora precisamente formulada, a passagem pode levar o leitor descuidado à conclusão de que Husserl defende que "primeiramente estamos dentro

\footnotetext{
${ }^{17}$ Ibidem, p. 31.

${ }^{18}$ CASANOVA, Marco Antonio. Mundo e historicidade: leituras fenomenológicas de Ser e Tempo - vol. 1: existência e mundaneidade. Rio de Janeiro: Via Verita, 2017, p. 31-32.

${ }^{19}$ HEIDEGGER, M. Metaphysische Anfangsgründe der Logik im Ausgang von Leibniz. Gesamtausgabe 26. Frankfurt: Vittorio Klostermann, 2007, p. 160-170.

${ }^{20}$ CASANOVA, Marco Antonio. Op. Cit., p. 32.
} 
para posteriormente experimentarmos o fora". Se, por um lado, um autor não é responsável pelo descuido de seus leitores, não se pode ignorar, por outro lado, aquilo que implicitamente o texto sugere: no caso, é-nos sugerido que Husserl endossaria o "pressuposto moderno mais evidente". Se antes se disse que a noção de consciência e similares precisam ser alijadas da noção husserliana de intencionalidade, agora se anuncia que Heidegger elimina qualquer pressuposto relacionado à noção de consciência de si ou auto-consciência. A pontual menção a Fichte, com a função de encontrar um alvo mais preciso para a crítica heideggeriana, certamente passa despercebida do leitor sem familiaridades maiores com Husserl.

De que se trata, então, em Husserl em meio à crítica heideggeriana das noções de consciência, auto-consciência, etc.? Como podemos interpretá-la fazendo jus também à indicação inicial do caráter promissor da noção de intencionalidade? Podemos certamente começar retomando a ideia aqui mencionada de uma reviravolta na economia conceitual da fenomenologia: reter a noção de intencionalidade sem manter a de consciência é já um abalo na economia conceitual da fenomenologia husserliana. Isso porque intencionalidade é uma das várias caracterizações de consciência. Nos parágrafos iniciais da Quinta Investigação Lógica, trata-se justamente de elucidar a polissemia da palavra consciência. Três noções de consciência, fundamentais para a fenomenologia, são aí introduzidas: a de fluxo de vivências, a de percepção interna e a de intencionalidade. Enquanto a noção de percepção interna é discutida com vistas à rejeição justamente de uma tese de autoconsciência mais exigente, as noções de vivência e de intencionalidade serão assimiladas à fenomenologia husserliana de modo central como dois sentidos de consciência. E embora os sentidos de vivência e intencionalidade sejam diferenciados, as chamadas intenções são in concreto propriamente uma classe de vivências: uma classe de vivências cujo caráter distintivo é justamente o de transcender o âmbito imanente do fluxo de vivências. É nesse sentido que Husserl, então, diz que nós já sempre ouvimos a melodia da cantora: estamos intencionalmente voltados não para sensações acústicas imanentes ao fluxo de vivências, ou mesmo aparições, mas sim à própria melodia enquanto objeto intencional que transcende esse fluxo mesmo. Estamos, para usar a expressão de Casanova, sempre - ou quase sempre - fora: em um "exterior" que tem claramente um ponto de referência "interior" no fluxo de vivências. Assim, já em Husserl nós encontramos uma fenomenologia que não adere à tese de que estamos "primeiramente dentro e posteriormente fora" - e isso justamente graças à centralidade do conceito de intencionalidade enquanto conceito de consciência. ${ }^{21}$

${ }^{21}$ Especialmente significativo nesse sentido é o Apêndice à Sexta Investigação Lógica em que Husserl se dedica a mostrar como percepção interna não possui nenhum privilégio epistêmico com relação à percepção externa. Cf. HUSSERL, E. (1901). Logische Untersuchungen. Bd. 2. Teil 2. Elemente einer phänomenologische Aufklärung der Erkentnis. $6^{\mathrm{a}} \mathrm{ed}$. Tübingen: Max Niemeyer Verlag, 1993, p. 222-244. 
O que não ocorre em Husserl, contudo, é a eliminação de qualquer referência à interioridade, a qual, como o formula Casanova, seria para Heidegger "não apenas inacessível, mas também inútil". Quando dizemos, então, junto com Casanova e Heidegger, que a intencionalidade não deve ser pensada no registro da consciência, então duas questões inevitavelmente se levantam: que gênero de coisas são intenções, uma vez que não são vivências? E de que modo se pode falar de transcendência se aquilo respectivamente ao qual se fala que intenções são transcendentes foi eliminado da descrição fenomenológica? Enquanto a primeira pergunta se deixa responder pela noção de comportamento-relacional (Verhalten, Verhaltung), a segunda se deixa compreender a partir da tematização da temporalidade originária, sobretudo a partir da noção de Entrückung ${ }^{22}$ e de nada originário. ${ }^{23}$ Não nos cabe, todavia, no âmbito dessa nota bibliográfica, desenvolver as respostas a essas perguntas, que exigiriam uma exegese mais ampla de Ser $e$ Tempo e do posterior desenvolvimento da metafísica do Dasein em que a Kehre começa a operar. Trago-as à tona para indicar (i) que Husserl não é um autor cartesiano prototípico e (ii) que, apesar disso, o movimento de Heidegger na direção de eliminação de qualquer noção de consciência é um radical abalo na economia conceitual husserliana, constituindo-se um desafio para qualquer interpretação que queira dar sentido à ideia de que a noção de intencionalidade é precursora da noção de movimento ekstático do Dasein. ${ }^{24}$

Ambos esses pontos repercutem diretamente na segunda questão que proponho levantar relativa à interpretação da relação entre Husserl e Heidegger: o estatuto do princípio de todos os princípios. Um exame minucioso desse princípio torna claro que ele, em Husserl, é fundamentalmente dependente da oposição entre conteúdos de consciência internos e externos, ou imanentes e transcendentes ao fluxo de vivências. Desse modo, se abrimos mão de qualquer referência àquilo que é imanente ao fluxo de vivências, perigamos perder a base que torna esse princípio significativo - interditando assim qualquer interpretação que entenda haver em Heidegger uma "reformulação do teor significativo" do princípio de todos os princípios. Examinemos em detalhe.

\footnotetext{
${ }^{22}$ HEIDEGGER, M. (1927). Sein und Zeit. Tübingen: Max Niemeyer Verlag, 2001, p. 339.

${ }^{23}$ Idem. Metaphysische Anfangsgründe der Logik im Ausgang von Leibniz. Gesamtausgabe 26. Frankfurt: Vittorio Klostermann, 2007, p. 252-273.

${ }^{24}$ Talvez o ponto de Casanova seja aquele defendido pelo primeiro heideggeriano no Brasil, Vicente Ferreira da Silva, quando afirmou que: "O homem interior do subjetivismo idealista, que transcende continuamente a objetividade que se lhe defronta através de uma polêmica interna, é o homem do dualismo cristão. A volta a si mesmo, que está à base do processo idealista é justamente a exposição, em termos filosóficos, da paixão religiosa instituída pelo cristianismo." SILVA, Vicente Ferreira. Obra Completas. São Paulo: É realizações, 2010, 3v., vol. II, p. 140, apud PAIVA, Thales Coimbra Paranhos Cavalcanti de. 2017. Elucidação da Temática Ontológica do Homem a partir dos Pressupostos Filosóficos na Obra de Vicente Ferreira da Silva. Dissertação (Mestrado em Filosofia). Universidade Federal do Rio de Janeiro. Rio de Janeiro, p. 105. 2017.
} 
Casanova cita e comenta a célebre passagem do § 24 de Ideias em que Husserl formula o princípio de todos os princípios. ${ }^{25}$ Cito a passagem original, em recorte e tradução diferente da de Casanova para efeitos de contextualização:

Basta de teorias absurdas. Nenhuma teoria concebível pode nos enganar quanto ao princípio de todos os princípios: de que toda intuição originariamente doadora seja legitimadora do conhecimento, de que tudo o que se oferece a nós na 'intuição' de modo originário (por assim dizer, em sua efetividade em carne e osso) deva ser tomado simplesmente como aquilo que ele se dá, mas também somente nos limites, nos quais ele se dá aí. ${ }^{26}$

Retornaremos a essa passagem abaixo. Comentando o princípio de todos os princípios, Casanova escreve:

Nós nos confrontamos, portanto, imediatamente com alguns termos que, para sermos rigorosos em nossa apresentação, são sistematicamente evitados por Heidegger: intuição, doação, realidade efetiva corpórea. Levando às últimas consequências o projeto de superação da metafísica da subjetividade, Heidegger contesta o caráter originário de algo assim como uma intuição originariamente doadora de objetos. De qualquer modo, porém, essa contestação não é suficiente para suspender o princípio de todos os princípios, ela apenas reformula o seu conteúdo significativo próprio, em termos não subjetivistas, ou seja, sem qualquer ligação com noções como consciência, ato de consciência, vivência, objeto correlato, etc. Ora, mas o que passa a estar em questão em tal reformulação? Dito de maneira sintética, a impossibilidade de pressupor a subsistência de algo para além do encontro descritivo com o seu próprio campo de manifestação. O que está em questão para o projeto fenomenológico heideggeriano não é mais por um lado alcançar uma intuição imediata do próprio fenômeno, enquanto correlato estrutural cooriginário da dinâmica de realização da vida da consciência. ${ }^{27}$

Eis, de acordo com Casanova, a transformação operada por Heidegger no princípio de todos os princípios: em uma fenomenologia hermenêutica, ele deixa de ser o princípio de uma intuição que nos dê diretamente -

${ }^{25}$ Embora Heidegger cite essa passagem em alguns de seus escritos, a opção de Casanova por essa passagem de Husserl - até mesmo na epígrafe de seu primeiro capítulo - não deixa de ser surpreendente. Isso porque, como se sabe, Heidegger, durante sua década fenomenológica, claramente preferia Investigações Lógicas a Ideias; Ideias, afinal, representa uma radicalização, no mínimo superficial, do aspecto cartesiano do pensamento de Husserl, tornando o diálogo com a fenomenologia de Heidegger mais difícil e a tentação de reduzir o pensamento de Husserl a um cartesianismo inócuo tanto maior; e, por fim e de modo mais relevante, em Ideias o próprio Husserl reconhece que o desenvolvimento do princípio de todos os princípios se faz sobre a base do que havia sido ganho na Sexta Investigação. ${ }^{26}$ HUSSERL, E. (1913). Ideen zu einer reinen Phänomenologie und phänomenologische Philosophie. Allgemeine Einführung in die reine Phänomenologie. 6 Edição. Tübingen: Max Niemeyer, 2002, p. 43-44.

${ }^{27}$ CASANOVA, Marco Antonio. Mundo e historicidade: leituras fenomenológicas de Ser e Tempo - vol. 1: existência e mundaneidade. Rio de Janeiro: Via Verita, 2017, p. 56. 
"imediatamente" - o próprio fenômeno, para ser o princípio do encontro descritivo das coisas em seus contextos de manifestação próprios - isto é, em seus mundos. De um lado, Husserl admitiria uma doação direta das coisas, de outro lado, Heidegger mostraria que todas as coisas se dão em seus contextos de manifestação.

Há duas questões que se podem levantar aqui: em primeiro lugar, ao fazer Heidegger substituir uma formulação por outra, Casanova nos sugere uma passagem sem intermediação. Ainda que se aceite que há verdadeiramente um salto entre Husserl e Heidegger, resta sem explicação por que o encontro descritivo com a coisa em seu campo de manifestação é uma transformação semântica do princípio de todos os princípios e não meramente outro princípio integralmente diverso - digamos, por exemplo, o princípio de respeito ao caráter contextual de todo encontro com as coisas elas mesmas.

Em segundo lugar, a passagem sugere que a diferença entre Husserl e Heidegger consiste naquela entre uma fenomenologia da doação imediata - intuição - e uma da mediação - mundo. Essa oposição parece-me por demais simplificada para dar conta da complexidade dos modelos de fenomenologia que cada autor desenvolve. Tanto a noção de intuição em Husserl envolve mediação intencional, quanto em Heidegger o encontro com entes é, por vezes, caracterizado de modo a sugerir um caráter intuitivo ou, quiçá, proto-intuitivo do encontro com os entes. Comento os dois pontos a seguir.

A noção de intuição em Husserl é central para a formulação do princípio de todos os princípios. Mas o que são intuições em Husserl? Não seriam, afinal, intenções que visam direta, isto é, imediatamente as coisas? Tudo depende aqui de como entendemos esse caráter imediato. Por um lado, pode-se dizer que intuições, em especial percepções, são modos imediatos de doação das coisas: em comparação com intenções signitivas, pictóricas e mesmo com intuições não perceptivas, intuições perceptivas são modos diretos de doação dos objetos. Por outro lado, mesmo a percepção só pode nos dar um objeto com a mediação de um sentido ou, conforme terminologia de Investigações Lógicas, de uma "matéria intencional": de um conjunto de determinações do objeto que funciona como princípio de identificação do objeto mesmo. Em última instância, na Sexta Investigação Lógica, é uma diferença na relação entre matéria intencional e o que Husserl chama de conteúdo apreendido que marca a diferença entre intenções signitivas e intenções intuitivas - uma diferença na relação entre conteúdos imanentes e transcendentes ao fluxo de vivências. Enquanto nas intenções signitivas, a relação é contingente-extrínseca, nas intuições, e em especial nas percepções, é interna-necessária. Assim, a dificuldade fundamental em sustentar que Heidegger mantém o princípio de todos os princípios se liga ao fato de 
esse princípio em Husserl estar sustentado numa fenomenologia que faz referência a elementos imanentes e transcendentes ao fluxo de vivências.

Tampouco a fenomenologia de Ser e Tempo se deixa encaixar facilmente no polo "mediato" da dicotomia imediato-mediato. Se, por um lado, o encontro com os entes se dá sempre já na mediação de um mundo previamente aberto, por outro lado, o descerramento enquanto tal é, frequentemente, caracterizado como sendo (i) uma visão, a saber, a visão do compreender e (ii) como sendo uma visão simples, singela. ${ }^{28}$ Se em passagens conhecidas Heidegger rejeita o privilégio do "intuir puro", a oposição "intuição" e "pensamento" e nominalmente a tese da intuição de essências, ${ }^{29}$ essa rejeição se liga, antes, à vinculação dessas noções a uma ontologia do ser simplesmente dado do que a uma rejeição completa de um acesso direto, isto é, imediato, às coisas mais próximas. Nesse sentido, é, a meu ver, mais sugestiva a conclusão de que Heidegger busca uma dimensão mais originária do intuir na noção de visão do compreender. ${ }^{30}$

Desse modo, se o princípio de todos os princípios deve poder ser aplicado de maneira transformada em Ser e Tempo, é um ponto importante que Heidegger retenha a caracterização de um ver imediato das coisas. Ainda assim, dado que esse princípio em Husserl se sustenta a partir da oposição de Investigações Lógicas entre conteúdos imanentes e transcendentes, não são poucos os desafios que se interpõem ao intérprete que pretenda sustentar essa tese.

Talvez, contudo, a ideia de que há em Heidegger um sentido de mediação absolutamente ausente em Husserl - e que assim justifique aquela oposição acima mencionada - se ligue, na proposta de Casanova, ao caráter hermenêutico da fenomenologia de Ser e Tempo. Aqui tocamos no ponto 1.3: Husserl teria incorrido em uma ingenuidade que poderíamos denominar de pré-hermenêutica. Com efeito, Casanova assim se exprime:

Em suma, por mais que tenha pensado seu projeto fenomenológico como concretização da ideia de filosofia como ciência rigorosa e, assim, como extensão do projeto husserliano, Heidegger acusa Husserl aqui de uma última ingenuidade: a ingenuidade de não se dar conta de que o círculo hermenêutico não se deixa suspender por meio da vontade, metodologicamente. ${ }^{31}$

\footnotetext{
${ }^{28}$ HEIDEGGER, M. (1927). Sein und Zeit. Tübingen: Max Niemeyer Verlag, 2001, p. 149.

${ }^{29}$ Ibidem, p. 147.

${ }^{30}$ Não posso deixar de registrar que em determinado momento o próprio Casanova toca nessa caracterização do ver do compreender ao caracterizar o encontro com manuais: "Em meio a contextos utensiliares, nós não concebemos propriedades, nós simplesmente imergimos no uso. A consequência disso é, por um lado, a imediatidade do encontro, e, por outro, a absoluta retração da rede referencial na qual os utensílios aparecerem." CASANOVA, Marco Antonio. Mundo e historicidade: leituras fenomenológicas de Ser e Tempo - vol. 1: existência e mundaneidade. Rio de Janeiro: Via Verita, 2017, p. 74.

${ }^{31}$ Ibidem, p. 192-193.
} 
Em Ser e Tempo, o círculo hermenêutico diz respeito às estruturas prévias da interpretação: ao interesse prévio ${ }^{32}$ (Vor-habe), à visão prévia (Vor-sicht) e à concepção prévia (Vor-griff). Husserl desenvolveria seu projeto sem se dar conta do encurtamento hermenêutico de seu interesse, visão e concepção prévios: Casanova se remete aí ao caráter inquestionado no âmbito da fenomenologia de Husserl (i) do problema com o qual começa seu trabalho, (ii) do privilégio de uma intuição originariamente doadora, e (iii) de uma conceituação sedimentada relativa a noções como consciência, vivência, etc. A epítome dessa cegueira para a dimensão hermenêutica estaria no aspecto voluntarista da epoché: a neutralização das posições ontológicas da atitude natural em Husserl se dá pelo exercício da vontade. Nesse sentido, a modificação hermenêutica da fenomenologia afetaria diretamente a epoché: enquanto liberação "das barreiras entre nós e os fenômenos como as coisas mesmas", a epoché não é questionada por Heidegger, apenas seu modo de realização o é. ${ }^{33}$ Se em Husserl eu poderia neutralizar as posições de existência como que de um só golpe com uma deliberação da vontade, em Heidegger se descobre uma dimensão mais rica de pressupostos, sob a rubrica da estrutura prévia da interpretação, declinável ademais historicamente, que não se presta à mesma atuação imediata.

É preciso, de início, se perguntar aqui: procede a tese de que Husserl tentaria suspender o círculo hermenêutico? Trata-se indubitavelmente de uma questão complexa que não se deixa resolver no âmbito de uma nota bibliográfica; em todo caso, gostaria de, em contraste com a resposta positiva de Casanova, sugerir aqui que é possível respondê-la negativamente.

Há três questões que podem ser levantadas contra a resposta positiva de Casanova. Em primeiro lugar, defender que Husserl suspende o círculo hermenêutico é possível apenas a partir da hipótese de que a estrutura prévia da interpretação é formada de pressupostos (quanto a isso, v. n. 6) - isto é, de posições prévias realizadas por um eu ou por uma consciência, como Husserl, por exemplo, em Ideias I expõe. Claro está que não se pode conceber a estrutura prévia como resultado de uma atividade de pôr ou de posicionar realizada por um eu/consciência. É parte central da fenomenologia de Ser e Tempo a luta contra a ideia de que o aparecimento

\footnotetext{
${ }^{32}$ Adoto tentativamente aqui a tradução de Vor-habe por "interesse prévio" para dar conta de um aspecto da expressão alemã: o verbo vorhaben significa pretender, ter a intenção de. Essa tradução certamente não capta o verbo ter, haben, parte do alemão, que certamente alude a uma posse prévia dos entes que já se desvelaram no mundo em que estou lançado - aspecto a que a opção de Castilho ("ter prévio") exclusivamente se refere. De todo modo, a tradução por "posição prévia", preferida por Schuback e por Casanova, conquanto sugira o posicionamento do Dasein (genitivo objetivo), isto é, seu caráter de estar lançado, arrisca-se por articular-se com o verbo pôr e com a noção de posição, caras à filosofia da subjetividade, que de modo geral entendeu ser como produto de uma posição realizada pelo sujeito. ${ }^{33}$ CASANOVA, Marco Antonio. Mundo e historicidade: leituras fenomenológicas de Ser e Tempo - vol. 1: existência e mundaneidade. Rio de Janeiro: Via Verita, 2017, p. 62.
} 
dos entes é de algum modo tributário de uma atividade de síntese e de posição de um eu ou uma consciência. Mesmo quando Heidegger fala da necessidade de pressupor a verdade, no $\S 44$ (c), é bastante claro que o esforço aí é o de superar o discurso sobre posição em favor da formulação de que a verdade se dá. ${ }^{35} \mathrm{Em}$ segundo lugar, é altamente questionável a leitura de que a epoché desconsidere dimensões hermenêuticas como sentidos, significados e mesmo interesses (v. abaixo) imanentes ao mundo da vida. Ao contrário, a neutralização em vista afeta apenas os posicionamentos de realidade próprios às ciências positivas e, eis um ponto problemático no Husserl de Ideias I, à atitude natural. Se entendemos a epoché desse modo mais preciso, então se torna compreensível também por que Heidegger, na preleção do semestre de emergência de guerra de 1919, caracteriza o vivenciar do mundo circundante (no original Umwelterleben) como nem dotado, nem desprovido de pressupostos, uma vez que ambas as possibilidades "têm sentido apenas no teóretico"36 (GA 56/57, p. 94). Dito de outro modo: a interpretação de que a epoché é a suspensão do círculo hermenêutico envolve uma ampliação do conceito de posição que, se não é ilegítima, é questionável.

Mas talvez se pudesse ponderar aqui que afinal Husserl esteve mesmo preso a um horizonte encurtado, sobretudo em suas obras publicadas em vida, de desenvolvimento da fenomenologia: não é o caso, como sugere Casanova, que Husserl permanece preso a certos problemas e projetos de teoria do conhecimento, a uma concepção de intuição como originariamente doadora e a uma conceituação própria à filosofia da consciência, todos elementos que estavam meramente disponíveis na tradição em que ele se inseria? Não seria esse, afinal, o ponto de Casanova ao atribuir a Husserl uma ingenuidade hermenêutica, a saber, o de que Heidegger questiona de modo mais radical certos pressupostos dados na tradição da metafísica da subjetividade? De minha parte, não há dúvida de que Heidegger o faz; contudo, que razões temos para ligar esse questionamento mais radical de Heidegger à dimensão hermenêutica propriamente dita de sua fenomenologia - e não à sua dimensão desconstrutiva? Se a acusação de ingenuidade hermenêutica contra Husserl não consiste na mera constatação de que vocábulos como "hermenêutico" não ocorrem em Investigações Lógicas, nem em Ideias I, mas estão presentes, sim, em Ser e Tempo - um registro vocabular não me parece ser o que Casanova está fazendo - então

\footnotetext{
${ }^{34}$ HEIDEGGER, M. (1927). Sein und Zeit. Tübingen: Max Niemeyer Verlag, 2001, p. 228.

${ }^{35}$ Não é por outro caminho que Tugendhat havia buscado explicar a ausência da epoché em Ser e Tempo: se nossa atitude pré-fenomenológica não é caracterizada por uma atividade de posição, então não faz sentido que nossa atitude fenomenológica se inicie por uma suspensão da posição geral. Qualquer tentativa de localizar a epoché em Ser e Tempo - como, por exemplo, Crowell o faz - deve, a meu ver, partir desse dado.

${ }^{36}$ HEIDEGGER, Martin. Zur Bestimmung der Philosophie. Gesamtsausgabe 56/57. Frankfurt: Vittorio Klostermann, 1987, p. 94.
} 
é fundamental que nós também nos perguntemos, inversamente, como localizar a dimensão hermenêutica na fenomenologia de Husserl. Dentre algumas possibilidades de fazê-lo, ${ }^{37}$ destaco aqui aquela que considero a mais auspiciosa: a literatura secundária sobre Husserl tem mostrado que a caracterização, em Ideias II, da atitude personalista nos indica claramente um âmbito co-extensivo ao âmbito hermenêutico em Ser e Tempo. Por atitude personalista, Husserl entende aquela atitude:

na qual estamos o tempo todo quando nós convivemos, falamos um com o outro, estendemos a mão em cumprimento um ao outro, quando nós estamos referidos um ao outro em amor e aversão, em pensamento e ação, em discurso e réplica; do mesmo modo, na qual nós estamos, quando nós consideramos as coisas dadas à nossa volta justamente como nosso entorno [Umgebung] e não ao modo da ciência natural como natureza "objetiva". ${ }^{38}$

A identificação entre a atitude personalista de Husserl e o plano hermenêutico da fenomenologia de Heidegger torna possível uma acusação reversa à da ingenuidade hermenêutica: a de que Heidegger, ao partir do foco exclusivo na dimensão hermenêutica, estaria necessariamente comprometido com uma perspectiva que tem como ponto cego justamente as dimensões infra de constituição dos objetos. Cito o clássico comentário de A.D. Smith de Meditações Cartesianas:

Ao fim da Terceira Meditação, por exemplo, Husserl fala de um "fundar por níveis" até o nível mais baixo de uma fundação da consciência do tempo interno. De fato, é Heidegger que é de algum modo um filósofo "uni-dimensional" no que se refere a isso, operando integralmente no nível da vida constituída, pessoal. Com Heidegger, a filosofia se torna mera hermenêutica. Husserl, ao contrário, vê a importância de clareza ulterior, na medida em que penetra abaixo do nível da vida pessoal, de modo a investigar camadas complexas da vida anônima constituidora, camadas que são pressupostas por qualquer explicação da nossa vida pessoal efetiva. ${ }^{39}$

Para essa perspectiva husserliana, tornar-se meramente hermenêutica significa aqui deixar de lado os diversos subsolos de constituição da realidade. ${ }^{40}$

\footnotetext{
${ }^{37}$ Gadamer, em Kant und die philosophische Hermeneutik, por exemplo, afirma: “Contra [...] esquematismos explicativos, a pesquisa fenomenológica como um todo, bem como a Psicologia descritiva e analítica de Dilthey orientada pelas ciências do espírito, pode se chamar 'hermenêutica' - em um sentido muito amplo -, na medida em que o conteúdo de sentido ou de essência ou a 'estrutura' de um 'fenômeno' não deve ser 'explicada', mas sim trazida à 'exposição interpretativa'." GADAMER, Hans-Georg. Kant und die philosophische Hermeneutik. Kant-Studien, 66(1-4), 1975, p. 396, doi:10.1515/kant-1975-0170, tradução nossa.

${ }^{38}$ HUSSERL, E. (1952). Ideen zu einer reinen Phänomenologie und phänomenologische Philosophie. Zweites Buch: Phänomenologische Untersuchungen zur Konstituition. Hua IV. Haag: Martinus Nijhoff, 1969, p. 183, tradução nossa.

${ }^{39}$ SMITH, A.D. Routledge Philosophy Guidebook to Husserl and the Cartesian Meditations. Londres: Routledge, 2003, p. 155, tradução nossa, grifo nosso.

${ }^{40}$ Uma objeção semelhante se encontra no ensaio Uma Filosofia da Ambiguidade de Alphonse de Waelhens, que antecede a edição de A Estrutura do Comportamento de Merleau-Ponty:
} 
Se bem que se possa considerar o fato, enfatizado por Casanova, de que Heidegger, fiel a esse aspecto hermenêutico, rejeita como fenomenologicamente inaceitável a diferença entre entes naturais e técnicos, é possível, pelas três questões levantadas acima, ao menos enfraquecer a tese de que Husserl buscaria suspender o círculo hermenêutico: Husserl não apenas abriria espaço para um âmbito hermenêutico como não deixaria que ele se tornasse o único acessível a uma descrição fenomenológica. Assim, às limitações óbvias da fenomenologia husserliana, ligadas à ausência de um projeto de desconstrução metafísica nos termos heideggerianos, se contrapõem as limitações de uma fenomenologia meramente hermenêutica, a qual, ao não aventurar-se no subsolo pré-hermenêutico ou pré-personalista de constituição, permaneceu, em princípio, alheia a um diálogo mais fecundo com dados das psicologias positivas (cf. n 9). Mas mesmo esse alheamento de princípio tem sido quebrado com as recentes apropriações de Heidegger por parte da ciência cognitiva. Discorro sobre essas apropriações a seguir.

Passo, assim, ao ponto 2): a fenomenologia do ente à mão e suas apropriações recentes no âmbito da ciência cognitiva. O comentário de Casanova menciona uma variedade de autores que se apropriaram de Heidegger por diferentes caminhos, tais como Figal, ${ }^{41}$ Gadamer, ${ }^{42}$ Loparic, ${ }^{43}$ bem como de comentadores, como Malpas ${ }^{44}$ e Reis. ${ }^{45}$. Nesse contexto, chama atenção o fato de que uma das assimilações mais influentes do pensamento de Heidegger não seja mencionada; refiro-me aqui às apropriações por parte da ciência cognitiva, apropriações que, inauguradas por Hubert Dreyfus - também responsável por um influente comentário de Ser e Tempo, ainda que igualmente polêmico -, abriram espaço para o diálogo entre fenomenologia e ciência cognitiva. Se hoje se pode falar de uma inteligência artificial heideggeriana, se hoje se pode discutir qual modelo de ciência cognitiva é mais genuinamente heideggeriano, se hoje se pode

\footnotetext{
“Heidegger sempre se coloca num nível de complexidade que permite imaginar resolvido o problema que nos ocupa. Pois é no estágio da percepção e do sensível que este deve receber seu tratamento decisivo. Ora, os projetos que, segundo Ser e tempo, engendram para nós a inteligibilidade do real já pressupõem que o sujeito da existência cotidiana levanta o braço, já que martela e forja, dirige seu olhar, já que consulta o relógio, orienta-se, já que anda de carro. Que um existente humano possa realizar essas diferentes tarefas não suscita nenhuma dificuldade, a partir do momento em que foram julgadas 'evidentes' sua capacidade de agir e de mover o corpo, sua faculdade de perceber. As evidências do senso comum nunca podem deixar de ser 'cerceadas', e o leitor de Heidegger percebe tarde demais que a acuidade minuciosa empregada pelo autor na descrição do mundo que projetamos teve por contraparte uma total negligência do mundo que para nós 'é já sempre aí'." DE WAELHENS, Alphonse. Prefácio "Uma filosofia da ambiguidade". In: Merleau-Ponty, M. Estrutura do Comportamento. São Paulo: Martins Fontes, 2006, p. XI -XII.

${ }^{41}$ CASANOVA, Marco Antonio. Mundo e historicidade: leituras fenomenológicas de Ser e Tempo - vol. 1: existência e mundaneidade. Rio de Janeiro: Via Verita, 2017, p. 8, n. 2, p. 9, n. 4

${ }^{42}$ Ibidem, p. 15, n. 8.

${ }^{43}$ Ibidem, p. 43, n. 23.

${ }^{44}$ Ibidem, p. 23, n. 16.

${ }^{45}$ Ibidem, p. 148, n. 83.
} 
falar mesmo de uma neurociência heideggeriana, isso se deve indubitavelmente ao trabalho pioneiro de Dreyfus, que mobilizou, dentre outros, Heidegger na sua crítica à inteligência artificial simbólica. É verdade, todavia, que desde a emergência desse estilo de leitura - p. ex. desde a publicação do comentário de Dreyfus - não faltaram os que entenderam que se trata aí de uma leitura seletiva de Heidegger, que privilegia sua descrição do mundo circundante, sua crítica ao cartesianismo e de modo geral os temas da primeira seção de Ser e Tempo. ${ }^{46}$ Os mais afiados críticos de Dreyfus e de outros cientistas da cognição supostamente heideggerianos podem certamente nos convencer de que teses naturalistas e cientificistas são imanentes ao projeto de ciência cognitiva e absolutamente alheias ao pensamento de Heidegger, ${ }^{47}$ ainda assim, se Gadamer está certo ao reconhecer na aplicação um momento da interpretação, ${ }^{48}$ então mesmo esse capítulo sui generis da história dos efeitos de Heidegger merece parte de nossa atenção, especialmente em passagens dedicadas à reconstrução de temas como a lida circundante, a espacialidade e o impessoal. Assim, por exemplo, ao reconstruir a descrição da lida circundante, Casanova, fiel à hermenêutica desconstrutiva, perpassa várias hipóteses que enviesariam a descrição, ${ }^{49}$ sem mencionar aquela, cuja rejeição ganha importância sem igual na assimilação de Dreyfus: a hipótese de uma dicotomia fato e valor.

Mas talvez o ponto em que de modo mais nítido se pode reconhecer a contribuição das ciências cognitivas no diálogo com a fenomenologia esteja na chamada questão da alteridade, isto é, do social, ou, como se costuma referir na tradição husserliana, da intersubjetividade. Com efeito, Heidegger tratou esse tema sob a rubrica do "ser-com" e Casanova indubitavelmente faz jus à proposta de Heidegger nesse quesito: de modo sintético, trata-se em Ser e Tempo de reconhecer que o Dasein é constitutivamente e cooriginariamente aos diversos momentos de ser-no-mundo ser-com. Isso significa que o estado social não é produto de um suposto "encontro efetivo entre os homens", ${ }^{50}$ isto é, entre indivíduos em estado pré-social. Casanova escreve: “Nós somos essencial e constitutivamente sociais e não há nenhuma possibilidade de pensar uma situação, na qual a experiência

\footnotetext{
${ }^{46}$ Ver p. ex. OLAFSON, Frederick A. "Heidegger à la Wittgenstein or 'coping' with Professor Dreyfus". Inquiry 37(1), 1994, p. 45-64 e REHBERG, Andrea. “Heidegger and Cognitive Science: Aporetic Reflections". In: Kiverstein, J.; Wheeler, M. (org.). Heidegger and Cognitive Science. Palgrave Macmillan. 2012.

${ }^{47}$ Cf. RATTCLIFFE, Matthew. "There Can Be No Cognitive Science of Dasein". In: Kiverstein, J.; Wheeler, M. (org.). Heidegger and Cognitive Science. Palgrave Macmillan, 2012 e, mais uma vez, REHBERG, Andrea. "Heidegger and Cognitive Science: Aporetic Reflections". In: Kiverstein, J.; Wheeler, M. (org.). Heidegger and Cognitive Science. Palgrave Macmillan. 2012. ${ }^{48}$ GADAMER, Hans-Georg. Wahrheit Und Methode. Grundzüge Einer Philosophischen Hermeneutik. Mohr, 1960, p. 312-316.

${ }^{49}$ CASANOVA, Marco Antonio. Mundo e historicidade: leituras fenomenológicas de Ser e Tempo - vol. 1: existência e mundaneidade. Rio de Janeiro: Via Verita, 2017, p. 107.

${ }^{50}$ Ibidem, p. 107.
} 
social não se faça presente." ${ }^{51}$ Assim, já as descrições que Heidegger fará da lida dos entes intramundanos envolverão a exposição das referências aos outros entes dotados do caráter de Dasein, ao "portador e usuário". ${ }^{52}$ Em última instância, mesmo nas possibilidades em que nos encontramos, de um ponto de vista objetivo, sozinhos, nós já estamos inseridos em um mundo compartilhado. Escreve Casanova:

Nós somos [...] seres-no-mundo que se encontram originariamente abertos para um campo existencial no qual jamais se tem a possibilidade de experimentar a solidão absoluta, justamente por que o espaço mesmo sempre se mostra como espaço compartilhado. ${ }^{53}$

Assim, fica interditada qualquer interpretação do Dasein a partir de uma perspectiva solipsista, que o opusesse, assim, aos outros entes dotados do caráter de Dasein. Em conformidade com isso, a própria noção de alteridade, no que se refere à fenomenologia hermenêutica, se modifica: a referência aos "outros" não diz respeito àqueles que eu não sou, mas, antes, àqueles dos quais eu não me diferencio. ${ }^{54}$

Do ponto de vista da exegese textual de Ser e Tempo, não há o que se objetar à reconstrução de Casanova. A questão a que chamo atenção aqui é a seguinte: seria essa descrição fenomenológica da alteridade suficiente? O recente trabalho de Gallagher e Jacobson (2012) sugere que não. Ressoando críticas à abordagem heideggeriana da estrutura ser-com feitas por autores tão diferentes quanto Löwith, Binswanger, Pöggeler e Theunissen, ${ }^{55}$ mas fundamentalmente apoiados em trabalhos recentes em áreas como a neurociência, a psicologia do desenvolvimento e a própria tradição fenomenológica (esp. Merleau-Ponty), Gallagher e Jacobson se alinham à Teoria da Interação (Interaction Theory) em filosofia da mente. Embora desenvolvida como crítica a outras teorias de filosofia da mente, como a Teoria da Teoria (Theory Theory) e a Teoria da Simulação (Simulation Theory), a posição da Teoria da Interação permite também a seguinte apreciação crítica com relação ao tratamento de Heidegger do ser-com: Heidegger negligenciaria a chamada intersubjetividade primária, o que repercutiria num caráter também limitado da abordagem da intersubjetividade secundária. ${ }^{56}$ Consideremos em detalhe a seguir.

Por intersubjetividade primária entende-se um conjunto de capacidades, já implícitas no comportamento interativo de recém-nascidos, de perceber

\footnotetext{
${ }^{51}$ Ibidem, p. 73.

${ }^{52}$ HEIDEGGER, M. (1927). Sein und Zeit. Tübingen: Max Niemeyer Verlag, 2001, p. 70.

${ }^{53}$ CASANOVA, Marco Antonio. Op. Cit. p. 125.

${ }^{54}$ CASANOVA, Marco Antonio. Mundo e historicidade: leituras fenomenológicas de Ser e Tempo - vol. 1: existência e mundaneidade. Rio de Janeiro: Via Verita, 2017, p. 127.

${ }^{55}$ GALLAGHER, S.; JACOBSON, R. "Heidegger and Social Cognition". In: Kiverstein, J.; Wheeler, M. (org.). Heidegger and Cognitive Science. Palgrave-MacMillan, 2012, p. 239.

${ }^{56}$ Ibidem, p. 223.
} 
imediatamente os outros, em seus gestos e expressões corporais. Rigorosamente, não se trata de uma percepção meramente observacional, mas, antes, de uma percepção do outro que faculta oportunidades para ação e imitação, interação e comportamento expressivo - donde o termo Teoria da Interação. Por intersubjetividade secundária, entende-se um conjunto de capacidades que dizem respeito à vinculação das ações a contextos sociais compartilhados: a partir de aproximadamente um ano de idade, as crianças aprendem como os outros interagem com um mundo e, assim, a "ligar ações a contextos pragmáticos", mas também, uma vez inseridas em contextos de atenção compartilhada, "o que as coisas são e para que elas servem" naqueles contextos. A intersubjetvidade secundária, que se soma a e aprimora as capacidades da intersubjetividade primária, diz respeito ao aparecimento dos outros em um mundo compartilhado - ao passo que a intersubjetividade primária se liga ao aparecimento dos outros em corpo presente. Não é difícil concluir que a descrição do ser-com em Ser e Tempo privilegia o que os autores denominam de intersubjetividade secundária em detrimento da chamada intersubjetividade primária. Mas mesmo no âmbito da intersubjetividade secundária, a capacidade chamada participatory sense-making, isto é, a capacidade de aprender com os outros a respeito do mundo compartilhado também é pouco desenvolvida fenomenologicamente em Ser e Tempo ${ }^{57}$ Assim, dado que Casanova enfatiza justamente o aspecto que foi alvo dessa crítica clássica, recentemente reforçada por Gallagher e Jacobson, é, a meu ver, oportuno em seu comentário uma tomada de posição a respeito do tema.

Passo assim ao quarto e último ponto desta Nota Bibliográfica: a reconstrução da questão da verdade em Ser e Tempo. Casanova revigora a crítica de Heidegger à concepção correspondentista de verdade ao problematizar o que poderíamos chamar de leitura compatibilista da verdade em Heidegger: de acordo com essa leitura, não é a verdade como adequação que é questionada por Heidegger, mas apenas a pretensão de que essa concepção seja a mais originária. Leitores como Dahlstrom ${ }^{58}$ tornariam o

\footnotetext{
${ }^{57}$ Em REIS, R. R. “Verdade e sacrifício na intencionalidade social”. In: O que nos faz pensar. Vol. 34. Março, 2014b, p. 145 - 170, o autor toca brevemente nessas objeções e, sumarizando a resposta de McMullin a Theunissen, defende que objeções dessa natureza partem de premissas questionáveis na leitura de Ser e Tempo (cf. ibidem, p. 148-149). Não há aqui espaço para discutir em detalhes a resposta de Reis. Faço notar aqui que a resposta permite apenas acomodar conceitualmente as dimensões ausentes de intersubjetividade à economia conceitual de Ser e Tempo. Uma vez que Gallagher e Jacobson não questionam a tese fundamental de Ser e Tempo de que o ser-com é constitutivo do Dasein, e uma vez que a negligência denunciada é decisivamente a de descrições fenomenológicas correspondentes a tais dimensões da intersubjetividade, parece-me que a resposta de Reis atinge apenas aquelas alegações mais fortes de Gallagher e Jacobson, a saber, a de que ser-com não inclui intersubjetividade primária. ${ }^{58}$ Embora apenas Dahlstrom seja citado no comentário de Casanova, é possível acrescentar nomes como Okrent, Dreyfus, Wrathall, que buscaram reabilitar a correspondência/adequação no âmbito da fenomenologia hermenêutica de Heidegger, isto é, com vistas ao caráter originário da verdade como desvelamento. Pode-se mesmo considerar que esse movimento
} 
caráter originário da verdade como desvelamento compatível com certa validade da verdade como adequação, correspondência, tomando por base o fato de Heidegger mesmo caracterizar a verdade como adequação como derivada. Contra essa leitura compatibilista, Casanova fornece, a meu ver, não tanto um argumento, quanto uma advertência, uma recordação. ${ }^{59}$ Tais leitores parecem, fundamentalmente, se esquecer de dois pontos: (i) o caráter decadente e sedimentado do mundo cotidiano já sempre atravessou e mediou os modos pelos quais nosso acesso às coisas aconteceu em contextos de adequação enunciativa, isto é, a adequação já sempre pressupôs a não-verdade enquanto velamento operado pelos preconceitos de nossa estrutura prévia da interpretação pública; (ii) no âmbito da descrição fenomenológica que já desobstruiu o caminho das vias sedimentadas de aparecimento do real, toda e qualquer distância entre descrição e descrito desaparece. Assim, conclui Casanova:

Com isto, a verdade como adequação se mostra como derivada do descerramento de mundo, mas tendo como fundamento a não-verdade, ao mesmo tempo em que a evidenciação do caráter de verdade como descerramento acaba por tornar caduco o discurso sobre adequação, uma vez que a descrição fenomenológica está para além de adequado e inadequado. ${ }^{60}$

Assim, não apenas a perspectiva da adequação envolveria um velamento essencial a partir dos preconceitos hermenêuticos cotidianos vigentes nos modos de decadência, como também a liberação de tais preconceitos implicaria uma dimensão na qual não há espaço para adequação, uma vez que encerraria um desvelamento direto dos entes. Mesmo que se quisesse resguardar um espaço para a adequação no âmbito da decadência, como o querem os leitores que chamei de compatibilistas, não se poderia deixar de considerar que, por um lado, esse espaço da adequação envolve um

\footnotetext{
de reabilitação da adequação no âmbito da fenomenologia de Heidegger é uma das marcas da interpretação analítica que emerge nos anos 90 do século XX. Na medida em que essa linha compatibilista parece não medir forças para extrair uma perspectiva adequacionista em Heidegger e assimilar Heidegger à tradição da filosofia analítica, a advertência de Casanova contra ela é sem dúvida bem-vinda. Todavia, nessa discussão, no mais das vezes se perdeu de vista que a abordagem da adequação relevante para Heidegger é a de Husserl - a única exceção é Okrent, que, entretanto, interpreta Husserl de modo fundamentalmente mentalista. Cf. OKRENT, Mark. Heidegger's Pragmatism: Understanding, Being, and the Critique of Metaphysics. Cornell University Press, 1988, p. 111-119; DREYFUS, Hubert L. "10 How Heidegger defends the possibility of a correspondence theory of truth with respect to the entities of natural science". P. 4--219 in Heidegger Reexamined, organizado por H. L. Dreyfus e MARCO ANTÔNIO. Wrathall. Routledge, 2002; WRATHALL, Mark. Heidegger and Truth as Correspondence. In: Dreyfus, H.(Org.). Heidegger Reexamined. Vol. 2: Truth, Realism and the History of Being.New York: Routledge, 2002.

${ }^{59}$ Que não se trate de um argumento, que visasse provar que esses leitores estão errados, se depreende do fato de que mesmo Casanova concorda com a tese de que a adequação tem seu lugar nos modos decadentes fáticos de existir, tese na qual se centra a leitura compatibilista. ${ }^{60}$ CASANOVA, Marco Antonio. Mundo e historicidade: leituras fenomenológicas de Ser e Tempo - vol. 1: existência e mundaneidade. Rio de Janeiro: Via Verita, 2017, p. 294.
} 
velamento essencial e que, por outro lado, a liberação dos fenômenos originários ocorre num âmbito em que nenhuma adequação é possível.

Três questões podem ser levantadas aqui - duas ligadas a essa argumentação e outra, de cunho geral, referente à questão da verdade em Heidegger. Em primeiro lugar, nota-se que Casanova se refere, ao fim, à descrição fenomenológica. Pode-se questionar se ela estaria mesmo para além do adequado e do inadequado. Explica-se: é certo que Heidegger, em praticamente toda sua obra, sustenta que o sentido de verdade primordial é o de desvelamento - no caso em questão, descerramento, descoberta; é certo também que esse sentido de verdade como acontecimento está para além do adequado e do inadequado; todavia, estende-se integralmente à descrição fenomenológica a estrutura da verdade originária? Dizer que sim é dizer que a descrição fenomenológica de algum modo repete esse acontecimento. É inevitável reconhecer nessa resposta positiva a identificação com a caracterização de Heidegger da obra de arte como pôr-se em obra da verdade. Procede, contudo, essa integral identificação? Parece-me que a descrição fenomenológica em Heidegger, desenvolvida sob a rubrica implícita do conceito de indicativo formal, interdita uma aproximação mais completa entre discurso fenomenológico e abertura acontecimental originária da verdade. ${ }^{61}$

Em segundo lugar, pode-se questionar a mencionada não distância entre descrição e descrito, enunciação e coisa enunciada: na passagem citada, Casanova sugere que a não distância é operada pela liberação dos preconceitos hermenêuticos da estrutura prévia. Todavia, a ideia de que no enunciado nós já estamos juntos às coisas, isto é, direcionados às coisas mesmas, não se restringe ao âmbito hermeneuticamente elucidado, mas diz respeito aos nossos enunciados apofânticos enquanto tais - ou seja, já na decadência sedimentada nós estamos junto aos entes eles próprios. Não à toa, tal caracterização do enunciado já figura em Husserl, ainda que de modo diferenciado: as visadas signitivas já se dirigem ao objeto mesmo. É, a propósito, esse gesto que é recuperado por Heidegger no famoso $\S$ 44 (a), quando nos diz que o enunciado se refere ao quadro torto e não a uma representação psíquica dele. ${ }^{62} \mathrm{O}$ mais importante disso tudo é que essa caracterização do enunciado em Husserl jamais foi suficiente para uma rejeição da adequação/correspondência - pelo contrário, a exigência do princípio de todos os princípios é a de uma doação das coisas mesmas

\footnotetext{
${ }^{61}$ REIS, Robson R. "Verdade e Indicação Formal: a hermenêutica dialógica do primeiro Heidegger". In: Veritas. Vol. 46, n. 4, dezembro 2001, p. 607 - 620.

${ }^{62}$ Nesse contexto, é mister marcar aqui que a referência de Casanova ao princípio de todos os princípios nesse contexto é, no mínimo, imprecisa. Enquanto no princípio de todos os princípios o discurso sobre a coisa ela mesma diz respeito à autodoação das coisas, no âmbito das visadas signitivas o discurso sobre coisa ela mesma diz respeito à mera visada vazia do objeto. Evidentemente, tudo depende de se reconhecer aqui certa flutuação de sentido no uso de "coisa ela mesma" por Husserl.
} 
tais como visadas. O caso de Husserl evidencia que a conclusão implícita de que não há espaço para a adequação porque a descrição e o descrito não se distanciam mais na fenomenologia hermenêutica é injustificada.

Uma última questão se impõe aqui com relação à verdade. Refiro-me à retração de Heidegger, no escrito tardio O Fim da Filosofia e a Tarefa do Pensamento, a respeito da noção de verdade. Nesse escrito, mas também em escritos posteriores, Heidegger inequivocamente desvincula verdade de desvelamento e indica que o tema do acontecimento de desocultação não se relaciona com o tema da verdade como adequação e correspondência. Reconhecendo o erro de ter vinculado os temas, mas também apontando para uma breve passagem do próprio Ser e Tempo que se mantém imune a esse erro $^{63}$ (cf. HEIDEGGER, [1953] 2001, p. 219), Heidegger parece abdicar de todo tratamento do acontecimento de desvelamento em termos de "verdade". A questão aqui é: como pensar o tratamento de Ser e Tempo à verdade e ao descerramento e descoberta dos entes à luz dessa retração?

Independentemente das questões de detalhe aqui consideradas, é indubitável que Mundo e Historicidade está destinado a ser um comentário padrão para a leitura de Ser e Tempo - poucos comentadores conduzem tão rapidamente o leitor iniciante a uma familiaridade com a obra de Heidegger como Casanova o faz. Sem descurar do rigor dos conceitos fenomenológicos e da precisão das descrições ali envolvidas, e, ao mesmo tempo, explorando exemplos prosaicos e referências do cinema e da grande literatura, Marco Antonio Casanova nos convida a mobilizarmos nossas situações hermenêuticas em favor do entendimento do que está em questão em Ser e Tempo. Gerações presentes e vindouras certamente ficarão em débito com Casanova. Espera-se, com essa Nota Bibliográfica, quitar parte dessa dívida.

${ }^{63}$ HEIDEGGER, M. (1927). Sein und Zeit. Tübingen: Max Niemeyer Verlag, 2001, p. 219. 